\title{
Importance of extended separation in NIR technology for secure secondary image identification, a survey
}

\author{
Ana Agić ${ }^{1}$, Denis Jurečić ${ }^{1}$ Darko Agić ${ }^{2}$, Klaudio Pap ${ }^{1,2}$ \\ ${ }^{1}$ University of Zagreb, Faculty of Graphic Arts \\ ${ }^{2}$ Croatian Academy of Engineering
}

\section{Summary}

For separation purposes image information is usually defined as RGB record, what will be converted in CMY, CMYK or some other suitable image processing procedure, for reproduction purposes. Applying specific and dedicated NIR separation we developed, secondary achieved image is hidden and secured. NIR image is based on absorption diversities of used basic inks as well other inks that should be separated. On that way we achieved optimal instrumental determining of secondary image. Basic postulate for effective CMYKIR separation and double image are twin dyes, theirs imposing and reflection differentiation of inks, that has to be carried out in in extended area. If differentiation is not managed properly, secondary image is not secured, and could appear incorrectly. Present photographic and printing options facilitate responsible and stable adjusting for steady double image recognition. We presented relevant NIR separation and twins principles at prepress/ press stages for extended experience, and some considerable implementation of technological and scientific aspects.

Keywords: CMYKIR separation, NIR image, ink carbon black, adjusted achromatic interchange, dual colors

\section{Introduction}

At graphic reproduction in visual area primary selection is performed when picture, graphic or generated image is practiced in image editing and correcting applications where separation process is carried out. Platemaking procedure and printing process are following steps. Human procurable visible area and color comprehension are granted along illumination source that is applied. Colors, hues, saturation, intensities and other visual experiences are provided by existing light absorption/reflection properties of all objects, media, materials that are surrounding us. Image capturing devices in visual area utilize RGB imaging system and additive color mixing principles. On the other side basic graphic reproduction utilizes standard subtractive color mixing principles using CMY, CMYK inks. It is possible to use some other dedicated color system such as hepta or hexachrome, or some other custom developed inks/color system. Standard graphic reproduction applies /for visual area/ subtractive separation forms for cyan, magenta, yellow and black ink. Prior to that step, conversion RGB to $\mathrm{CMY}(\mathrm{K})$ color models as well as printing parameters for chosen printing procedure has to be done [1], [2]. For the purpose for twin colors creating for hidden image demand, adequate achromatic interchange has to be performed [3], [4]. Such procedure leads to double image formation in extended area. [5], [6]. For secondary image visualization we developed appropriate instrumental procedure. Procurable photographic equipment has to be attuned, so specific features upon imaging and visualization at NIR (Near Infra Red) technology could be practiced for extended instrumental experience [7], [8].

\subsection{Visual domain separation}

Primary color separation intended for visual domain usually is made by photographic or imaging equipment by capturing luminous and chromatic characteristics of target object. RGB to printing CMYK purposes is usually a programming module incorporated in image correction and manipulation applications. A CMM (color management module) procedure connects color spaces, and ensures optimal reproduction, gamut and image range for chosen printing procedure (for visual area). Embedded 
achromatic function [9], [10] in image correcting apps for NIR purposes exhibits not suitable, so we withdraw that approach and developed our own. In literature we perceived some appliance of hidden image, but visual only monochromatic [11], [12]. Correction modules incorporated in image correction apps support variety of specifications described as ICC (International Color Consortium) profiles and ISO (International Organization for Standardization) regulations. Unfortunately, numerous optical characteristics of numerous interesting substrates and dyes for NIR technology are neither described and nor defined. They have to be analyzed, specified, and cataloged.

Aimed separation with involved infrared twin colorants is published in works established on new theoretical postulates named CMYKIR [15], [16]. Recent works include spectroscopic valuation with twins dyes equality confirming in visual domain, and diversity in NIR spectral domain [17]. Appliance of IRD process is comprehensive in textiles where textual information is hidden in clothes [18]. Security printing on transparent foils with invisible contents is applied for exotic products as instance for expensive aronia sauces [19].

\subsection{Extended NIR separation}

NIR technology we dedicated invented for extended image perception often utilizes (for standard reproduction) non standard substrates, media and inks. Procedure incorporates standard separation and reproduction for visual domain, but also absorption/reflection properties for process and other suitable materials in expanded and extended NIR domain. Expanded area is responsible for secondary image, we can describe it as "secondary selection", and its instrumental determination as exhibition quality of secondary image [13].

Separation module described at initial investigations is soon partially changed, widened, and supplemented with additional operational performances. So stability of secondary image is assured. As the NIR process is performed alongside to visual, achromatic module is adjusted and customized for NIR developing and originating suitable and appropriate "twin colors". Alternative procedure of "visual achromatic interchange" in NIR technology accepts fixed achromatic rate at twin color pairs "twins", generating. As twins are essential in visualization process in visual area but in NIR also, their mutual ratio has to be strictly defined, but custom designed for visual and NIR domain [14].

Professional aid for such investigations was made with forensic analyzing optical device Projectina 4500, covering spectral and barrier investigations in observed domain. (Ultra Electronics Forensic Technology, www. projectina. ch). Fig. 1 shows spectral properties of Wratten filter series that can be used in NIR domain optical investigations, from barrier scanning to $\mathrm{Z}$ image visualization.

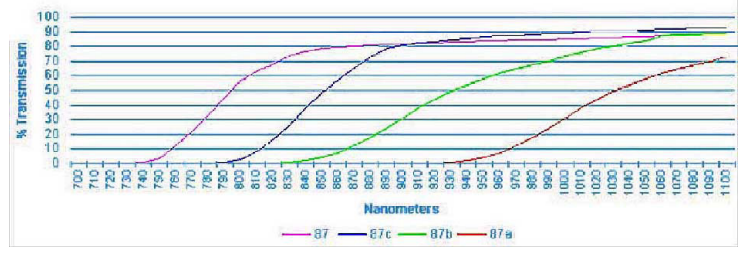

Figure 1. Spectral properties of Wratten filter series suitable for NIR investigations, Wratten 87 a is suitable for $Z$ camera adjustment and secondary image visualization, $87,87 \mathrm{c} 87 \mathrm{~b}$ are suitable for barrier scanning.

\section{Twin pairs in visual and extended domain}

Graphic arts practiced achromatic interchange allows defining und generating a variety of the same experience colors, including "color twins". We are showing this possibility as a dedicated example, while combining various coverage $\mathrm{CMY}$ and $\mathrm{K}$ inks, Fig. 2 and Fig. $3 \mathrm{AB} 1$ is a $\mathrm{CMY}+\mathrm{K}$ combination and $\mathrm{AB} 2$ is pure $\mathrm{CMY}$ combination.

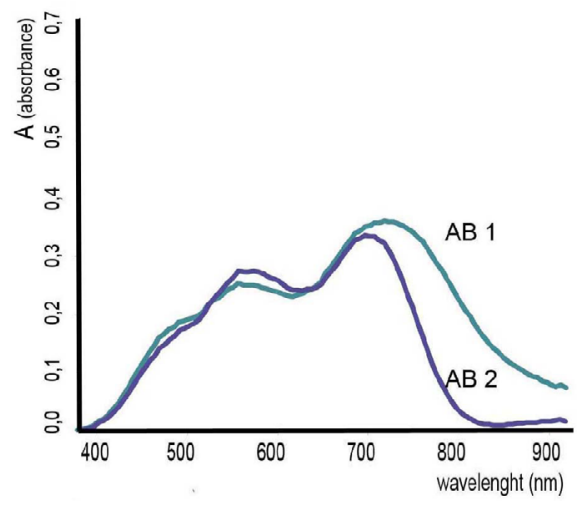

Figure 2. Spectral curves of a twin pair $A B 1$ and AB2 (example) (analysis made with forensic system Projectina4500, by Ultra Electronics Forensic Company, courtesy dr. J. Žiljak) 


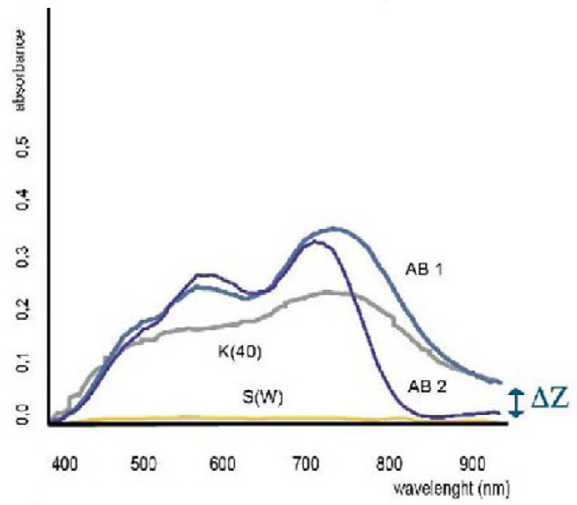

Figure 3. Absorbance spectral curves from chosen white substrate (SW), black ink $\hat{a}_{K}=0.4$ (K40), $K=40$ achromatic interchange twin ( $A B 1)$, and only process inks twin only process inks (AB2). Forensic spectral device Projectina, Ultra Electronics Forensic Company applied, courtesy dr. sc. J. Žiljak

Coverages are so adjusted that visual response for twin pair is quite the same, and absorption curves are overlapping. In NIR domain absorption behavior if the twin pair is different. Such behavior is suitable for extended experience and instrumental visualization possibility. Information about spectral absorption behavior in NIR (700-1000 nm) for various substances are mainly not examined and available. These parameters we have to specify for each single case, so by surrounding tuning process, reproduction parameters would be adjusted for practical but efficient reproduction purposes. Most visualization imaging devices are sensitive up to $1200 \mathrm{~nm}$, so with proper adjustment they can be used separate for visual and/ or for NIR purposes. That adaptation ensures $\mathrm{Z}$ image visualization, but also could be used for investigation absorption/reflection properties of dyes and materials from visual domain to $\mathrm{Z}$ domain.

\subsection{Achromatic interchange domain}

As stated before, standard color management intended for color managing in visual area, as well as achromatic principles are incorporated in image processing and manipulation apps. According to digital data arrangement, achromatic option offers "no, low, middle or high" interchange rate. This implies that the rate can differ from one position to another on the picture, according to pixel value specially at high color pictures (nature). This can lead us to variety of $(\mathrm{CMY})+\mathrm{K}$ values at recalculating, and instability of secondary image. At the same time
ICC (International Color Consortium) recommends TAC (Total Area Coverage) as productive criteria for selected reproduction process and applied for visual. Such approach in not an optimal solution, and advisable is not recommended for secondary secured hidden image. The reduction principle is improved and set to a fixed reduction amount, so most NIR implementations are made on that way. According to NIR principles we improved basic programming module including achromatic interchange, screening elements shape, adjusting twins, enhancing colors etc. Fixing twin interchange amount to $\mathrm{K}=40 \%$ coverage $\left(\hat{\mathrm{a}}_{\mathrm{K}}=0.4\right)$ in the whole image keeps twins balance. This $\hat{\mathrm{a}}_{\mathrm{K}}=0.4$ is achieved experimentally and satisfies needs and compromises making secondary image stable and secured. Twin pair in "chromatic" area should not differ visually. Colorimetric difference $\Delta \mathrm{E}$ is supposed be as low as possible, what implies overlapping spectral curves. Extended area differentiates twins according to CMY coverage group and CMYK coverage group as absorption behavior. A regression method analysis is carried out for approximate coverages tuning, so defining of printing properties is lightened and accelerated. Fig. 3. is presenting typical spectral curves of a twin pair. In visual, approximately 400-700 nm, spectral curves practically overlap. This proves that in visual twin pair, CMY and CMYK arrangement shows the same output, and low instrumental (colorimetric $\Delta \mathrm{E}$ ) values.

Twins pair coverage combinations of basic process dyes (example $A B 1, A B 2$ ):

$\mathrm{AB} 1$ pair (achromatic interchange $\mathrm{K}=40 \%$ )

C 60 - M20 - Y 0 - K40

$\mathrm{AB} 2$ pair (process dyes only)

C100 - M60 -Y 40 - K 0

Spectral area above $750 \mathrm{~nm}$ is out of human sense. Unfortunately, red filter unwanted transparency partially covers this area. This can lead to unwanted influences and deformations, such as unwanted influence of cyan color in final secured image, that can harm secondary secured image. We underline that twins spectral curves in expanded area should be clearly separated.

Expanded area is followed by $\mathrm{Z}$ area where spectral curves must stay clearly disconnected. In such situation $\mathrm{Z}$ camera single valued 
accepts vision widening role, and displays-visualizes secondary secured image. That's the way how human visualization experience is widened. Colors (ink combination) where achromatic interchange is not applied (CMY twin) produce lower absorption factor (higher reflectance), while twin achieved with achromatic interchange has higher absorption factor (lower reflectance). Difference between absorbance/reflectance colors in $\mathrm{Z}$ area leads to $\Delta \mathrm{Z}$ contrast, where accomplished secondary separation facilitates instrumental visualization of the extended experience.

\subsection{Visual and NIR resolving}

In visual area "color separation" is performed on a way that is modulated for screen or printing purposes. For printing purposes we describe that (primary) subtractive colors carry out separation states, forming separate printing forms. Other colors in a printing form are represented as nonprinting elements. According to autotypic principles fourth color can be black, usually designated as key (K). Sequence of printing forms originates color reproduction. In visual viewing this coloration situation is visual enabled, while in extended area is different, as shown on Fig. 3.

We must point out that spectral absorption curve of $\hat{\mathrm{a}}_{\mathrm{K}=} 0.4$ renders similar shape as achromatically realized twin, particularly in extended area. At the same time absorption rate of CMY combination twin in extended area approximates to the (white) substrate absorption. This describes also the upper limit of the $\mathrm{Z}$ response, as well as $\Delta \mathrm{Z}$ yield.

\section{Some highlighted examples of dual image technology, a survey}

We accept the fact that any color, dye, pigment, substrate, media or substance that surround us, expresses some specific absorption/reflection features at preconditioned illumination conditions. Standard graphic arts reproduction is mostly interested in "visible" part of spectrum. There is appearance of different spectral behavior in visible (V) and NIR (IR) domain of some inks, process inks, spot colors and/or some certain acceptable media. According to such diversity we appointed basic principles of dual images consistency.
$4 a$

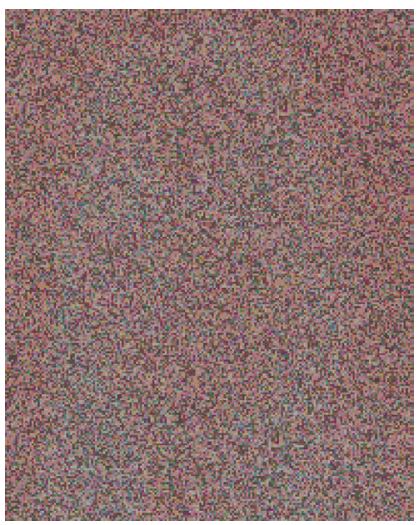

$4 d$

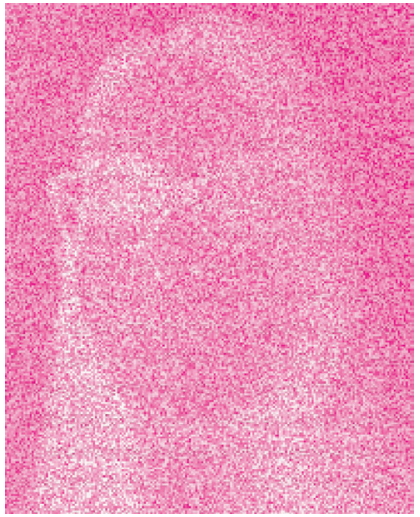

$4 b$

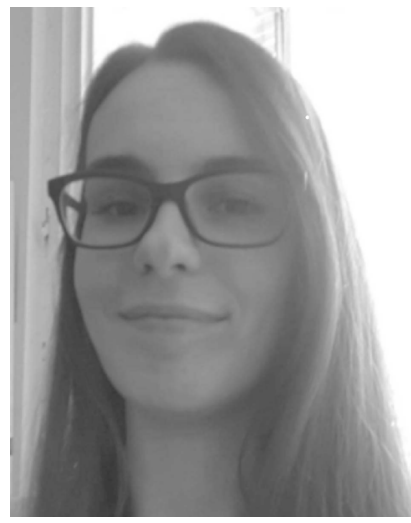

$4 \mathrm{e}$

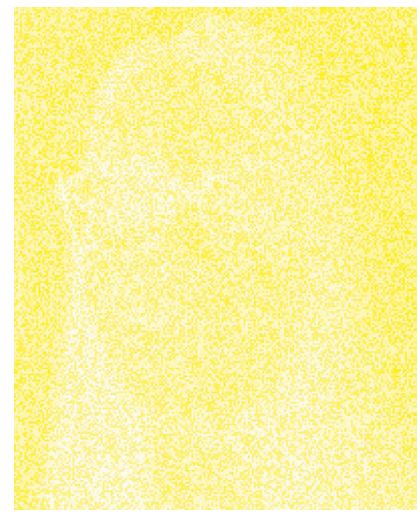

$4 c$

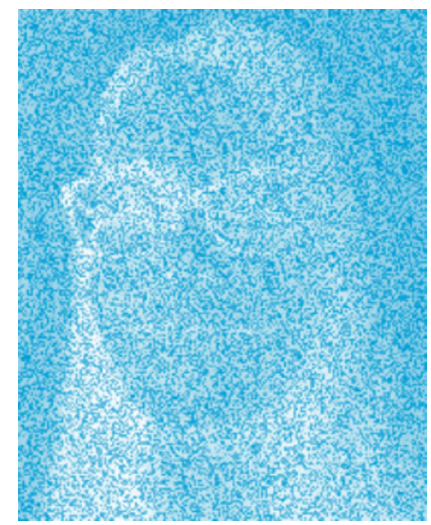

$4 f$

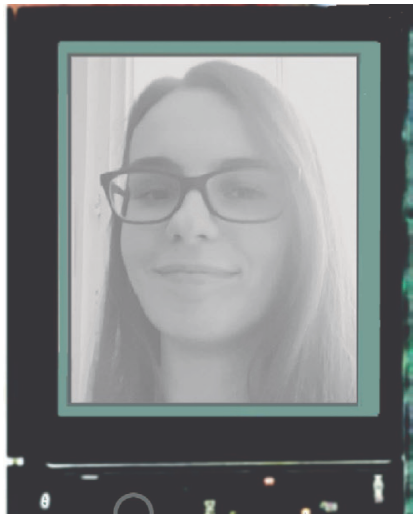

Figure 4. Example of a portrait embedded in multicolor visual model. Visual image consists of numerous stochastic arranged colored elements (4a), portrait provided for secondary graphic (4b), oversight of channels C (4c), M (4d), $Y$ (4e), and image appearing in Z camera stage (4f) (courtesy dr. J. Žiljak) 
Some of our incipient works are linked to monochrome visual appearance. They expressed explicit significance and requirement for stability of predicted dual colors. Importance of dedicated reproduction parameters tuning is crucial. Standard reproduction reduction rate is advanced to linear predefined rate of $\mathrm{K}$ coverage $\left(\hat{\mathrm{a}}_{\mathrm{K}}\right)$. As shown of Fig. 4 reproduction conditions are stable. Transferring the file without detailed coverages customization to another printer will cause images instability, ghosting and similar disadvantages. Repeated scanning, reimaging and similar actions and reproduction are not acceptable. They do not express desirable result, so originally of dual images is preserved.

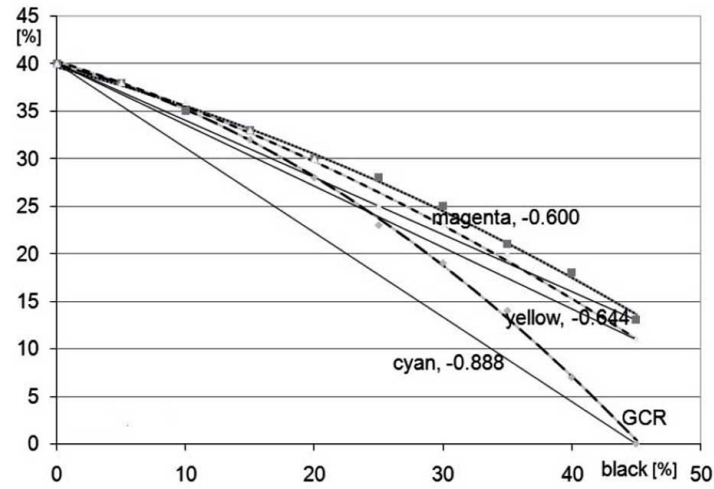

Figure 5. CMY reproduction trendlines of reduction coverages for targeted printer

For enhancing reproduction parameters of twin colors we managed regression analysis of some colors. Fulfilled reduction functions some facts were manifested: coverage tendency trend is not linear, and differs for each observed color (dye), Fig. 5. Regression analysis can be carried out for determining corrected values that approximate to demanded values of twin dyes. Furthermore we developed some dedicated program procedures and modules for more accurate adjusting of twin dyes, according to results already published. Numerous cognitions, especially on material properties that were used for dual and secured images implementations were found out, especially on materials, dyes and substrates with very diverse compositions.

Wide field of creative possibilities are opened to designers, technologists, scientists and other scopes of interest

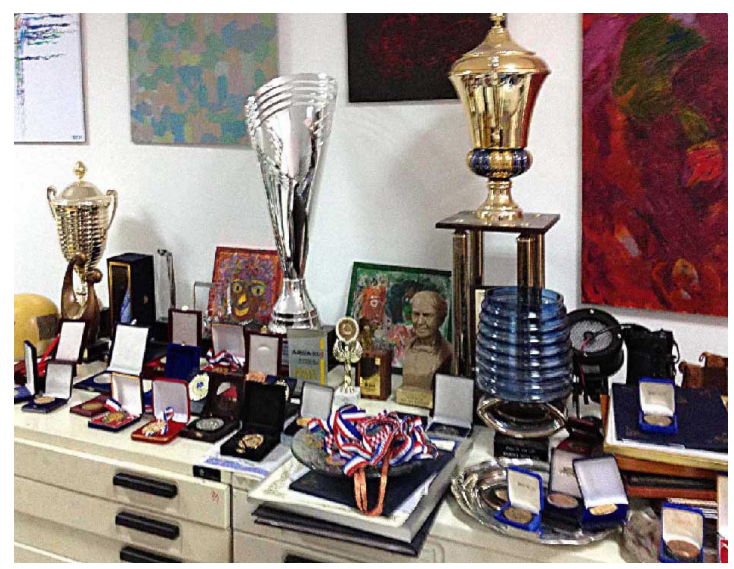

Figure 6. Some rewards and special rewards achieved in Geneva, Moscow, Pittsburgh, London, listed in affix.

Ensuring printing in newspaper rotation, we proofed stability and consistency of dual image reproduction and its implementation on large graphic arts systems, where during reproduction there is no possibility of any additional correction and adjusting. The achieved reproduction result was foreseen.

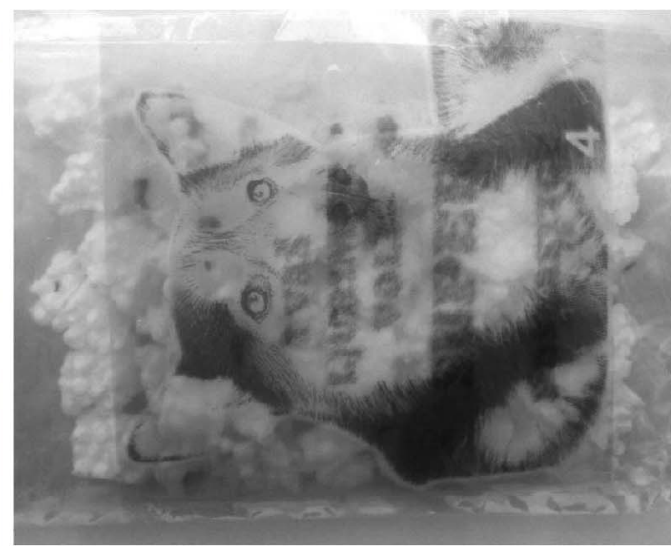

Figure 7. Dual image on transparent_substrate, visual and Z image (courtesy dr. J. Žiljak) 


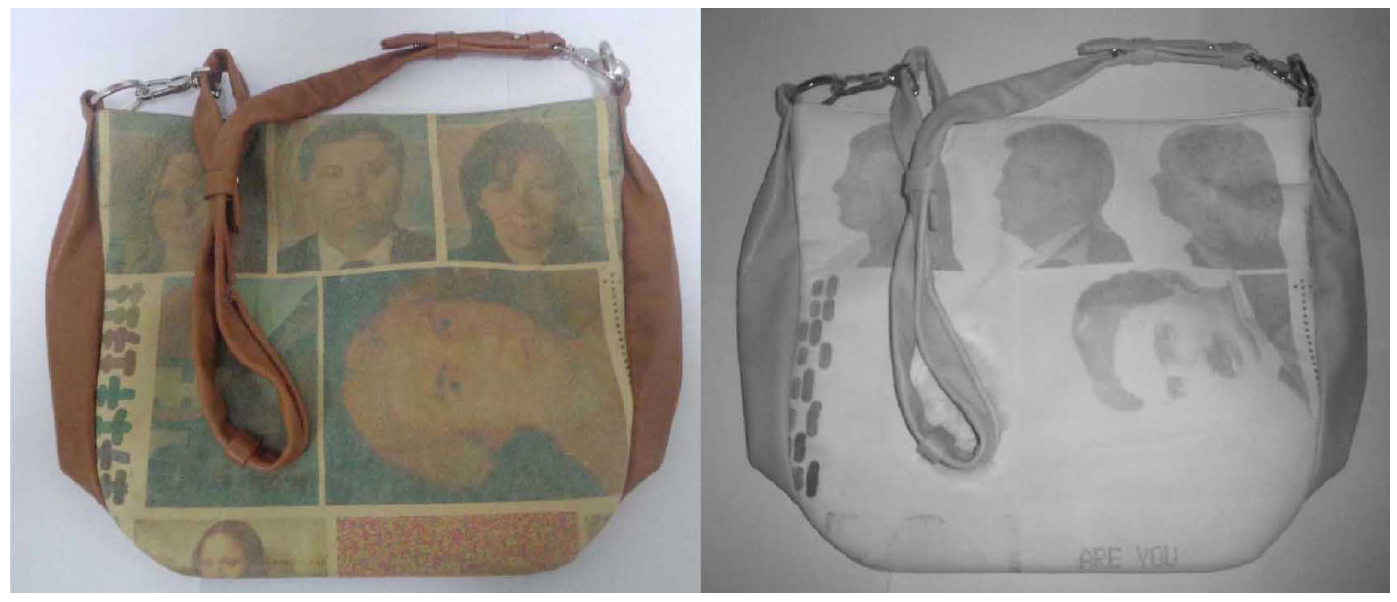

Figure 8. Safety print on leather product, visual image left, Z image, right (courtesy dr. J. Žiljak)

One of interesting implementation of dual image technology we made is the one on transparent substrate for food packaging (Fig. 7).

Achievement on transparent substrate is important for various reasons. Printing is made by flexographic process. That assumes letterset principles, inks properties different from offset or ink-jet ones. Transparent, polypropylene substrate-foil accepts inks different, where admitting ability, soaking-absorbing and stabilization differ from paper and similar materials properties. That successful realization confirms ambiguity of dual images implementing at rather different imaging systems, as well as stability at long run printing.

Meaningful example is also print on leather. Substrate, used inks and reproduction process partially differs from common or usual

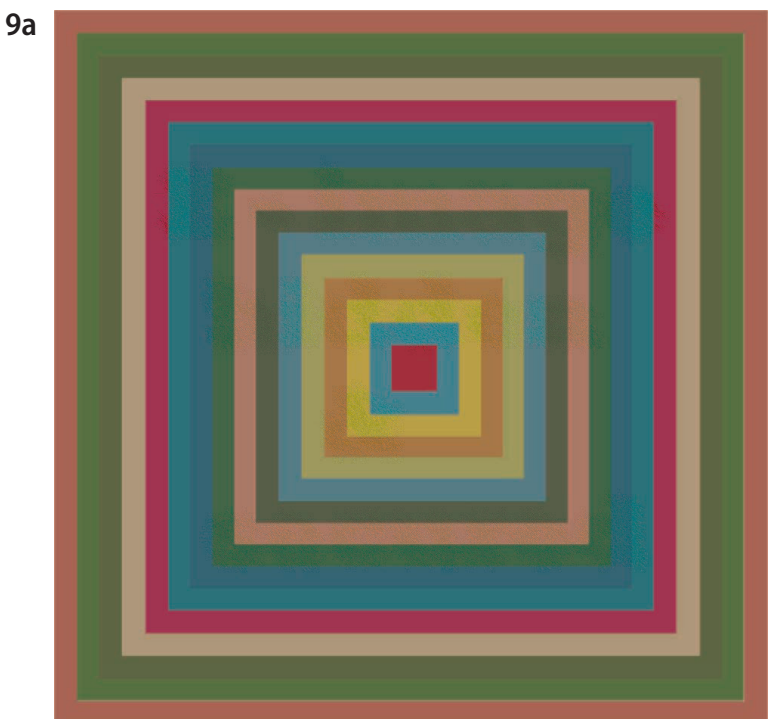

physical and chemical printing conditions usually used, Fig. 8. Process of dual images creating was also successful, what also proved versatility of appliance, at the same time ensuring originality and specificity of the product.

Following example represents possible coordination at dual image merging with safety elements in a specific and sensible field of multiple safety for dedicated graphics. This is a situation when new security measures are needed against forgery and providing authenticity. In that field some innovations and patent laws are introduced. Realized safety elements are based on hidden image technology in NIR domain, within visual image design of huge colors based on Pantone or other scale colors, Fig. 9. No matter on numerous colors, standard CMYK separation is carried out with aim of

Figure 9. Example of selected colors at dedicated programmed double graphics, VIS (Fig 9a), and NIR (Fig.10b) whereat dedicated halftoning is applied. (courtesy) 
correction equations of CMYKIR separation. With help from this support, twin colors for dual images with corresponding $\mathrm{CMY}+\mathrm{K}$ coverages. are defined. Standard screening/autotypic procedure is changed with dedicated elements shapes.

Elements with distinct shape irregularity are designed and incorporated in widened spectral area graphic. Secondary image elements shape dispersion improved its hiding. Designing such sensitive product as customized graphic containing numerous colors but with standard separation, with known $\mathrm{Z}$ parameter is a specificity. Assessments for extended area and possible spot colors for offset printing are made. Extended CMYKIR separation model surrounding for numerous colors we modified for such dedicated designing purposes. High standards are applied at richly graphics, achieving double yield dimension for dedicated product, such as at limited size for special graphics.

\section{Conclusions}

We showed a brief review of CMYKIR technology development from first visually monochrome images to achieved multicolor expressions, combining process dyes and widened spot colors. We used various printing techniques and procedures, customized screening and other reproduction ways that can improve security and authenticity of a product.

Secondary graphic, secured and hidden in NIR domain broadens visual experience possibilities. This procedure we can apply to a variety of fields of interest and miscellaneous materials. CMYKIR separation procedure, coordination and equalizing of twin dyes we permanently broaden and enhance. Technological aspect is already on such development level that there practically is no material or dye that we could not apply for broadened experience. Uncovered technological areas are reducing, but spectral visual and NIR properties of multitude materials are still not defined. Information base about visual, NIR and other properties of various materials is still missing. That is still further task for scientists, designers, technologist and other interested curious persons to find out more about CMYKIR technology, double images, materials and dyes, and to find further areas of appliance and usage.

\section{References}

1. Žiljak-Vujić J, Agić A, Agić D, Politis A. E: ExpandING Double Hidden information With Infrared Dyes, 46 Annual International Conference on Graphic Arts and Media Technology Management and Education, 2014, Athens, Greece

2. Bernašek A, Žiljak Vujić J, Uglješić V: Vizualni i infracrveni spektar za bojila digitalnog tiska, Polytechnic and Design, Vol. 2. No 2. 2014. TVZ, ISSN 1849 - 1995; DOI: 10.19279/TVZ.PD.2014-2-2-03

3. Čaljkušić I, Hoić A, Žiljak Vujić J: The Reproduction of a Visual Work of Art with its Visual and Infrared State PRINT, ISBN 9789537064204 , CIP NSK: 8433142013.

4. Matas M, Rajendrakumar A, Žiljak Vujić J, Hoić A: The Role and Significance of a Designer in Postage Stamp Design with Infrared Graphics, Printing \& Design 2013, Centar za grafičko inûinjerstvo Akademije tehničkih znanosti Hrvatske, p: 11 -13, ISBN 9789537064204, CIP NSK: 8433142013.

5. Žiljak Vujić J, Pogarčić I, Sabati Z: Digital Print of Documents Containing the Infrared Protection of Information, Juraj Dobrila University of Pula, Faculty of Educational Sciences; New Possibilities of ICT in Education, ed. Ružić-Baf M, Žufić J, Pula, 2016. pp 103-112; CIP record is available from the University Library in Pula under No. 140530068 CIP Pula 140530068; ISBN 978-953-7320-28-7

6. Žiljak Vujić J, Crnjac S, Mitrović O: Development of the New Protection Processes and Services for Secure Printing, 14th International Design Conference-DESIGN 2016, Cavtat, Dubrovnik-Croatia, May 16-19, 2016. Faculty of Mechanical Engineering and Naval Architecture, Zagreb, Proceedings 429- pp: 21972204; ISSN 1847-9162, ISBN 9771847916007

7. Žiljak Gršić J: Near Infrared Spectroskopy in Print Technology, Polytechnic \& Design Vol. 5, No. 1, 2017. pp 32-36; DOI: 10.19279/TVZ.PD.2017-5-1-05

8. Agić A, Žiljak Vujić J, Agić D:Metoda namjenskog podešavanja za dvojne boje"- nužni postupak za vizualnu i NIR sliku, Polytechnic and Design Vol. 3, No 2, 2015, Zagreb, 2015, pp 170-174. ISSN 1849 - 1995, DOI 10.19279

9. Agić D, Agić A, Bernašek A: Blizanci bojila za proširenje infra informacijske tehnologije; Politechnic \& Design; Vol. I, No. I, 2013. pp: 27-32; ISSN 1849 - 1995; DOI 10.19279

10. Pogarčić I, Agić A, Matas M: Evaluation of the Colorant Twins for the Neutral Grey Spectra in Infrared Graphic Procedure, Tehnički vjesnik 23, 6(2016), pp 1659-1664; ISSN 1330-3651, ISSN 1848-6339; DOI: 10.17559/TV-20150303132036 ; Hrčak ID: 169526

11. Wang Li, Wang, S.J: A Black Generation Method for Black Ink Hiding Infrared Security Image, Applied Mechanics and Materials, Trans Tech Publications, Switzerland, Vol. 262 (2013), pp. 9-12. DOI: 10.4028/www.scientific.net/AMM.262.9

12. Chambers J, Yan W, Garhwal A, Kankanhalli M: Currency Security and Forensics: a Survey, Multimedia 
Tools and Applications; 2015, Volume 74, Issue 11, pp 4013-4043, DOI https://doi.org/10.1007/s11042 013-1809-x

13. Vujić Ž. J, Morić B, Rudolf M, Friščić M: Postage Stamps with hidden Information in Security Z Values: Technics Technologies Education Management, Vol. 8/4,/2013; p: 1466- 1473; ISSN:1840-1503, e-ISSN 1986-809X;IF0.414; http://www.ttem.ba/ ttem_8_4_web.pdf

14. Rudolf M, Koren T, Žiljak-Vujić J: New Postage Stamp Design With Tone Gradation in Infrared Design Technology, Acta Graphica 23(2012)3-4, 57-64 Hrčak ID: 101924, ISSN 1848-3828

15. Pap K, Žiljak I, Žiljak-Vujić J: Image Reproduction for Near Infrared Spectrum and the Infraredesign Theory, Journal of Imaging Science and Technology, vol. 54, no. 1, pp. 10502-1-10502-9(9); 2010

16. Žiljak V, Pap K, Žiljak I: Infrared hidden CMYK Graphics, The Imaging Science Journal, Vol 58. Issue 1; (2010); 20-27; ISSN: 1368-2199 ; Online ISSN: 1743-131X, p:20-27, imsmpa 045.3d DOI: 1179/136821909X12520525092882

17. Jurečić D, Žiljak V, Tepeš Golubic L, Žiljak Gršic J: Spectroscopy of colorants for fine art in visual and near infrared spectrum, Second International Conference on Applied Physics, System Science and Computers; APSAC 2017

18. Agić D, Anayath R., Gršić J, Agić A, Žiljak V: Hidden NIR dual image technology printed on the fabric, Polytechnic \& design, Vol. 5, /Issue 2, DOI: 10.19279/ TVZ.PD.2017-5-2-05, 2017

19. Moric Kolaric B, Grgic M, Jurečić D, Miljkovic P: Sigurnosna etiketa soka od aronije skanirana u blokadama u bliskom infracrvenom spektru, Polytechnic\&Design, Vol 5. No4, p:280-286; 2017; DOI: 10.19279/TVZ.PD.2017-5-4-12

\section{Some of special rewards for related topics achieved:}

* Grand Prix of Geneva and Gold Medal at the 37th Salon of Inventions, Innovations and New Products in Switzerland, Geneva, Switzerland 2009

* First Prize in the Category of "Creative and Innovative Project or Program of Creative Industry," Ivana Žiljak, Zagreb, 2009

* (2) Special award for creative innovation from Taiwan Invention Association and Silver Medal,

* (2) Double Gold and Silver Medal at the $9^{\text {th }}$ British International Innovation Show, London, 2009.

* Special award for Innovation, European Exhibition of Creativity and Innovation, Euro Invent, IASI Romania, London, 2009

* IFIA award for best innovative invention, Genius Europe International Invention Fair, Budapest, 2009

* Special Award for Best Innovation, "Infraredesign", The First Inventors and Researches in L.R. Iran, ARCA 2009

* Annual Award "Nikola Tesla" for the best Croatian innovator, Croatian Association of Innovators, INOVA 34, Zagreb 2009

* (2) Kuala Lumpur, MTE - Malaysia Technology Expo, the Best Invention, Gold Medal \& Malaysian Association of

* (2) Gold Medal \& GRAND PRIX first runner-up with a cash prize, INPEX 2010, Invention \& New Product Exposition, Pittsburgh, PA, USA

- City of Zagreb Award 2010.

- Best Croatian Innovation, Croatian Association of Innovators 35. INOVA

- Diamond award \& Gold medal, The 10th British Invention Show \& Awards, British Innovation \& Technology Show, 13-16 October 2010, London, UK 